\title{
Short communication: In vivo screening platform for bacteriocins using Caenorhabditis elegans to control mastitis-causing pathogens
}

\author{
S. J. Son, ${ }^{*} †$ M. R. Park, ${ }^{*}$ S. D. Ryu, ${ }^{*}$ B. E. Maburutse, ${ }^{*}$ N. S. Oh, $¥$ J. Park, $\S$ S. Oh, ${ }^{11,2}$ and Y. Kim ${ }^{\star 1,2}$ \\ *Department of Animal Science and Institute of Milk Genomics, Chonbuk National University, Jeonju 561-756, Korea \\ †Agency of National Food Cluster, Gwacheon, 427-806, Korea \\ †R\&D Center, Seoul Dairy Cooperative, Ansan, Kyunggi 425-839, Korea \\ $\S$ Department of Veterinary Internal Medicine, College of Veterinary Medicine, Chonbuk National University, Iksan 570-752, Korea
}

\begin{abstract}
This study aimed to develop an in vivo screening platform using Caenorhabditis elegans to identify a novel bacteriocin for controlling the mastitis-causing pathogen Staphylococcus aureus strain RF122 in dairy cows. Using Bacillus spp. isolated from traditional Korean foods, we developed a direct in vivo screening platform that uses 96-well plates and fluorescence image analysis. We identified a novel bacteriocin produced by Bacillus licheniformis strain 146 (lichenicin 146) with a high in vivo antimicrobial activity using our liquid $C$. elegans-Staph. aureus assay. We also determined the characteristics of lichenicin 146 using liquid chromatography-mass spectrometry and confirmed that it shared homologous sequences with bacteriocin family proteins. In addition, RNA-sequencing analysis revealed genes encoding cell surface or membrane proteins ( $S A B 0993 \mathrm{c}$, $S A B 0150, S A B 0994 c$, and $S A B 2375 c$ ) that are involved in the bactericidal activity of lichenicin 146 against Staph. aureus strain RF122 infection as well as those encoding transcriptional regulators $(S A B 0844 c$ and $S A B 0133)$. Thus, our direct in vivo screening platform facilitates simple, convenient, cost-effective, and reliable screening of potential antimicrobial compounds with applications in the dairy field.
\end{abstract}

Key words: bacteriocin, Caenorhabditis elegans, in vivo screening platform, mastitis-causing pathogen, Staphylococcus aureus

\section{Short Communication}

Mastitis in dairy cows is defined as an inflammation of the udder caused by a variety of microorganisms

\footnotetext{
Received April 18, 2016.

Accepted July 20, 2016.

${ }^{1}$ These authors contributed equally to this study.

${ }^{2}$ Corresponding authors: osangnam@gmail.com and ykeys2584@ jbnu.ac.kr
}

that gain access to the interior of the mammary glands through the teat canal. It is a chronic wasting disease and leads to substantial economic losses in dairy farms due to reproductive disorders, reduced milk production, and a decreased lactation period in dairy cows. Moreover, it poses a serious threat to the health of consumers because it can result in degradation of the quality of raw milk (Schukken et al., 2011).

Diverse microorganisms, such as bacteria, mycoplasma, yeasts, and algae, have been implicated as causes of mastitis (Watts, 1988). In general, 4 common bacteria (i.e., Staphylococcus aureus, Streptococcus agalactiae, Streptococcus dysgalactiae, and Streptococcus uberis) cause 90 to $95 \%$ of all infections in dairy industry (Miles et al., 1992); among them, Staph. aureus is the main mastitis-causing pathogen (Ikawaty et al., 2009). To treat and prevent mastitis infections, the use (and misuse) of antibiotics has been widespread in clinical and veterinary medicine during recent decades (Sears et al., 1995). The number of somatic cells and the use of antibiotics are closely related to mastitis (Ruegg and Tabone, 2000; Mungube et al., 2005); however, the use of antibiotics to control mastitis should be carefully considered because it may lead to antibiotic residues in the bodies of treated cows or transfer of antibiotics to raw milk through mammary glands and blood. Thus, residual antibiotics may accumulate in the meat and milk from treated cows. The presence of residual antibiotics in milk is not only undesirable from a public health perspective, but can also cause problems in fermented dairy products such as yogurt, cheese, and ice cream (Allison, 1985). Therefore, many methods have been developed to identify new natural antibacterial substances, including bacteriocins, which are generally defined as antimicrobial peptides that are synthesized ribosomally by bacteria and secreted into the extracellular milieu, where they usually act against closely related species without affecting the producer strain (Klaenhammer, 1993); thus, bacteriocins may be useful alternatives to antibiotics for the control of mastitis. These natural bacteriocins are particularly suitable 
given their use and acceptance as preservatives in foods (O'Shea et al., 2013).

Various methods have been employed to screen bacteriocins from probiotic bacteria. Of these, the most frequent method is simple in vitro assays, including well diffusion, because of the difficulty involved in screening active bacteriocins from several candidates in direct animal models. In addition, because of concerns over animal welfare, it is difficult to perform in vivo toxicity and survival assays using animals (Dawkins, 2012). To overcome these limitations, we developed a direct in vivo screening platform using Caenorhabditis elegans as a new in vivo model. Caenorhabditis elegans is a small, living soil nematode that feeds on bacteria and has been extensively used as an experimental system in biological studies because of its simplicity, transparency, ease of cultivation, and suitability for genetic analysis (Riddle et al., 1997). Caenorhabditis elegans-pathogen infection models have been used in several studies exploring pathogenesis as well as in screens for compounds with antimicrobial activity (Irazoqui et al., 2010; Rajamuthiah et al., 2014). The aim of this study was to develop a direct in vivo screening platform using $C$. elegans for bacteriocins produced by Bacillus spp. from traditional Korean foods to control mastitis-causing pathogens and to characterize the novel bacteriocin identified by proteomic and transcriptomic analysis.

Staphylococcus aureus strain RF122 provided by Sergine Even (INRA, Rennes, France; Bouchard et al., 2013) was used as the representative mastitis-causing strain in this study. Bacillus spp. were isolated from traditional Korean foods such as soy sauces, red pepper paste, and soybean paste (Yun et al., 2014). Staphylococcus aureus was cultured at $37^{\circ} \mathrm{C}$ in brain heart infusion (BHI) medium (BD Biosciences, Sparks, MD) for $18 \mathrm{~h}$ at $180 \mathrm{rpm}$. Bacillus spp. were cultured at $30^{\circ} \mathrm{C}$ in Luria Bertani or de Man, Rogosa, and Sharpe (MRS) medium (BD Biosciences). Cultures were maintained at $-80^{\circ} \mathrm{C}$ in cryoprotectant containing $50 \%$ glycerol for long-term storage. All strains were subcultured 2 times before the experimental analysis. The $C$. elegans strain used in this study was $g l p-4(b n 2) ; s e k-1(k m 4)$ double mutant strain (Kim and Mylonakis, 2012). This nematode strain was routinely maintained on nematode growth medium plates seeded with Escherichia coli OP50, as described previously (Park et al., 2013).

First, to prepare bacteriocins from Bacillus spp., bacterial strains were cultured in MRS broth at $30^{\circ} \mathrm{C}$ and $150 \mathrm{rpm}$ and then harvested by centrifugation at $3,000 \times g$ for $10 \mathrm{~min}\left(4^{\circ} \mathrm{C}\right)$. Cell-free supernatant was collected and filtered through a sterile $0.2-\mu \mathrm{m}$ syringe filter (Sartorius, Gottingen, Germany). The antimicrobial activity of Bacillus spp. was then determined with antibiotic-resistant pathogens, including methicillinresistance Staph. aureus (MRSA) strain MW2 and COL and vancomycin-resistant Enterococcus faecalis (VRE) strain VS583 (Kim and Mylonakis, 2012), as well as mastitis-causing Staph. aureus strain RF122 as an indicator strains using the disk diffusion method, as described previously (Yun et al., 2014). Antimicrobial activity was determined based on the production of a clear zone of inhibition on the agar.

Next, to develop the in vivo screening platform for bacteriocins using $C$. elegans, the $C$. elegans glp4(bn2);sek-1(km4) worms at the young adult or L4stage were infected with Staph. aureus RF122, which had been cultured overnight in BHI medium at $37^{\circ} \mathrm{C}$. Synchronized young adult or L4 nematodes were transferred to plates seeded with Staph. aureus strain RF122 for $24 \mathrm{~h}$ at $25^{\circ} \mathrm{C}$. After washing 3 times with M9 buffer (3.0 g of $\mathrm{KH}_{2} \mathrm{PO}_{4}, 6.0 \mathrm{~g}$ of $\mathrm{Na}_{2} \mathrm{HPO}_{4}, 0.5 \mathrm{~g}$ of $\mathrm{NaCl}$, and $1.0 \mathrm{~g} \mathrm{NH}_{4} \mathrm{Cl}$ for $1 \mathrm{~L}$ ), the nematodes were transferred into the wells of 96-well plates using a washer or dispenser (EL406, Bio-Tek; approximately 15-20 worms in each well). Each well contained $200 \mu \mathrm{L}$ of assay medium (20\% bacteriocin and $80 \%$ M9 medium, vol/vol). In addition, chloramphenicol at a concentration of $90 \mu \mathrm{g} /$ $\mathrm{mL}$ was used as a positive control and MRS broth alone was employed as a negative control. After incubating for $3 \mathrm{~d}$ in a humidified incubator at $25^{\circ} \mathrm{C}$, the pathogen and other remains were washed from the wells using an automated washer. To selectively stain dead worms, SYTOX Orange (Life Technologies, Carlsbad, CA) was dispensed into each well at a final concentration of 1.0 $\mu M$. The plates were then sealed and incubated at $25^{\circ} \mathrm{C}$ in a humidified incubator. After incubating for $24 \mathrm{~h}$, the plates were visualized using a fluorescent microscope (IX53, Olympus, Tokyo, Japan) to capture both transmitted light and fluorescent images (Figure 1).

The characteristics of the novel bacteriocin were also determined using proteome analysis. After ultrafiltration through 3-, 10-, and 30-kDa membranes (AmiconUltra-15, Millipore Corp., Billerica, MA), a fraction of the target bacteriocin was separated by Tricine-SDS-PAGE (Schägger and Von Jagow, 1987). The gel was fixed and one half of the gel was stained with Coomassie blue R250 (Precision Plus Protein Dual Xtra Standards, Bio-Rad, Hercules, CA), before destaining, and the position of the active bacteriocin was determined. To localize bacteriocin activity, the second half of the gel was washed with deionized water, overlaid with BHI soft agar in a plate inoculated with $1 \%$ of the overnight-cultured Staph. aureus RF122 as an indicator strain, and then incubated overnight at $37^{\circ} \mathrm{C}$. Furthermore, the target bacteriocin was identified using liquid chromatography-tandem mass spectrometry 
(LC-MS/MS; model 4800; Applied Biosystems), as previously described (Lee et al., 2014). The MASCOT algorithm (Matrix Science, Boston, MA) was used to identify peptide sequences present based on a protein sequence database.

To explore gene regulation in Staph. aureus strain RF122 in the presence or absence of the selected bacteriocin, whole-transcriptome analysis was performed by RNA-sequencing (RNA-Seq). Staphylococcus aureus strain $\mathrm{RF} 122$ was inoculated into $20 \mathrm{~mL}$ of assay medium with or without the selected bacteriocin $(20 \%$ bacteriocin and $80 \%$ M9 medium, vol/vol). The flasks were statically incubated at $25^{\circ} \mathrm{C}$ for $6 \mathrm{~h}$. The cells were then harvested by centrifugation at $9,000 \times g$ for $5 \mathrm{~min}\left(4^{\circ} \mathrm{C}\right)$. To extract high-quality bacterial RNA, an RNeasy Protect kit (Qiagen, Hilden, Germany) was used with an RNeasy mini kit (Qiagen) according to the manufacturer's protocol. The Ribo-Zero rRNA removal kit (Epicentre, Madison, WI) was used for ribosomal RNA depletion according to manufacturer instructions.
Libraries for Illumina sequencing were made with the TruSeq Stranded mRNA sample prep kit (Illumina, San Diego, CA) following the manufacturer's protocol. The RNA-seq was performed on the Illumina HiSeq 2500 platform using single-end 50-bp sequencing. The genome sequence of Staph. aureus strain RF122 was retrieved from the NCBI database (accession number NC_007622.1). The relative transcript abundance was measured as reads per kilobase of exon sequence per million mapped sequence reads (Mortazavi et al., 2008). Visualization of mapping results and differentially expressed gene analysis were performed using CLRNASeq program (Chunlab, Seoul, Korea).

For exploring antibacterial activity of selected bacteriocin to dairy environments, we obtained fresh soil samples from local dairy farms (Jeollabuk-do, Korea). The soil samples $(10 \mathrm{~g})$ were suspended with M9 buffer with or without selected bacteriocin and incubated at $25^{\circ} \mathrm{C}$ for $24 \mathrm{~h}$ with agitation. And then, each suspension were plated on the standard plate count (BD Biosci-

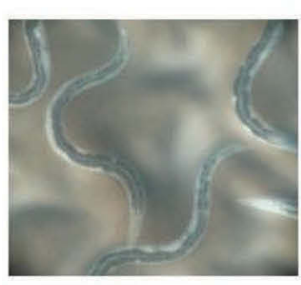

1. RF122 infection
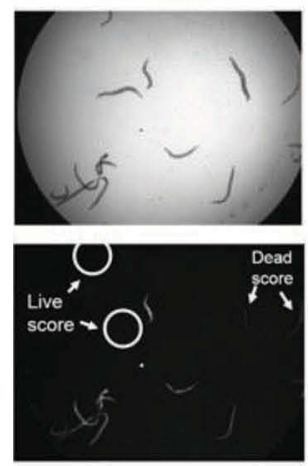

6. Analysis

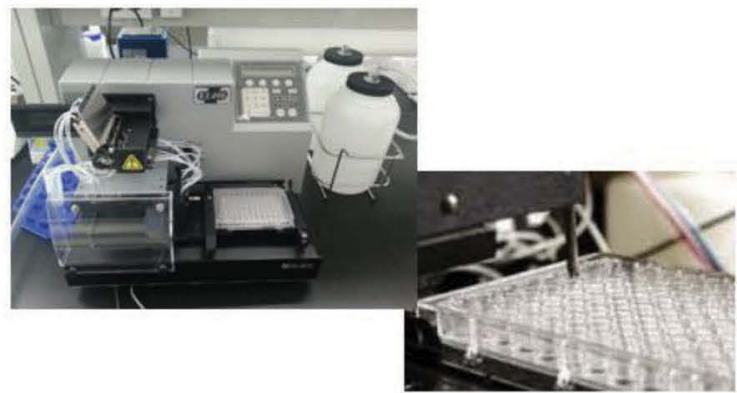

\section{Sorting worm ( $n=15-20$ per wells) and bacteriocin treatment}



3. Incubation



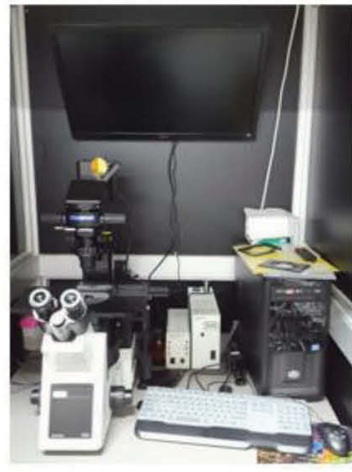

5. Imaging


4. Washing/SYTOX

Figure 1. Schematic of procedure of in vivo screening platform for bacteriocins using Caenorhabditis elegans. RF122 = Staphylococcus aureus strain RF122; SYTOX = SYTOX orange stain (Life Technologies, Carlsbad, CA). Color version available online. 
ences) agar for enumeration of total bacteria, including potential mastitis-causing pathogens.

As previously reported (Yun et al., 2014), among 300 strains isolated from traditional Korean foods, the cellfree filtered supernatants of selected health-promoting Bacillus spp. had specific antibacterial activities against various gram-positive pathogens including Micrococcus luteus and Bacillus cereus. In the present study, we used the disk diffusion method to show that, among the 300 isolated strains, 19 strains of Bacillus spp. possessed inhibitory activities against mastitis-causing Staph. aureus strain RF122 (data not shown). In particular, a bacteriocin isolated from B. licheniformis strain 146 (isolated from soybean paste Doenjang) had an antimicrobial activity against Staph. aureus strain RF122. Importantly, we showed that this bacteriocin possessed additional antimicrobial activity against to antibioticsresistant pathogens, such as MRSA and VRE strains. Antibiotics-resistant microbes have frequently been reported in dairy environments, even though they appeared with low prevalence. Among them, MRSA and VRE strains poses a serious threat to emergence of bovine mastitis in a dairy herd (Haran et al., 2012). To our knowledge, the current study is the first description of a dairy-associated bacteriocin that possess strong antimicrobial activity against mastitis-causing Staph. aureus as well as MRSA and VRE strains.

Further, using the in vivo $C$. elegans liquid assay, we determined whether the antimicrobial substance produced by Bacillus spp. could enhance the viability of nematodes in an in vivo environment. We used MRS broth alone and chloramphenicol $(90 \mu \mathrm{g} / \mathrm{mL})$, which is a common antibiotic used in the treatment of bovine mastitis (Fitzgerald et al., 2001), as negative and positive controls, respectively. To distinguish dead worms from live worms, we employed the SYTOX staining method, which is a convenient method for counting dead $C$. elegans under a fluorescent microscope because SYTOX Orange is excluded by living cells whereas it readily enters cells with damaged membranes, thereby staining dead worms (Rajamuthiah et al., 2014). Using the C. elegans-Staph. aureus liquid assay, the survival rates of 18 out of 19 screened strains were approximately less than $10 \%$, including 18 strains that exhibited inhibitory activity in the in vitro disk diffusion assay. Based on the number of SYTOX-stained nematodes (dead worms) in the fluorescence images, B. licheniformis strain 146 specifically enhanced the survival of C. elegans when infected with mastitis-causing Staph. aureus strain RF122 (survival rate of $74 \%$ compared with the chloramphenicol control; Figure 2A). In agreement with the results obtained using the in vivo platform, the antimicrobial activity of B. licheniformis strain 146 was confirmed based on its effect on the lifespan of $C$. elegans in a manual killing assay, as previously described (Kim and Mylonakis, 2012; Figure 2B). According to the results of our study, compared with the in vitro disk diffusion assay (Figure 3A), the liquid C. elegans-pathogen infection assay facilitates more effective screening to identify potential bacterio-
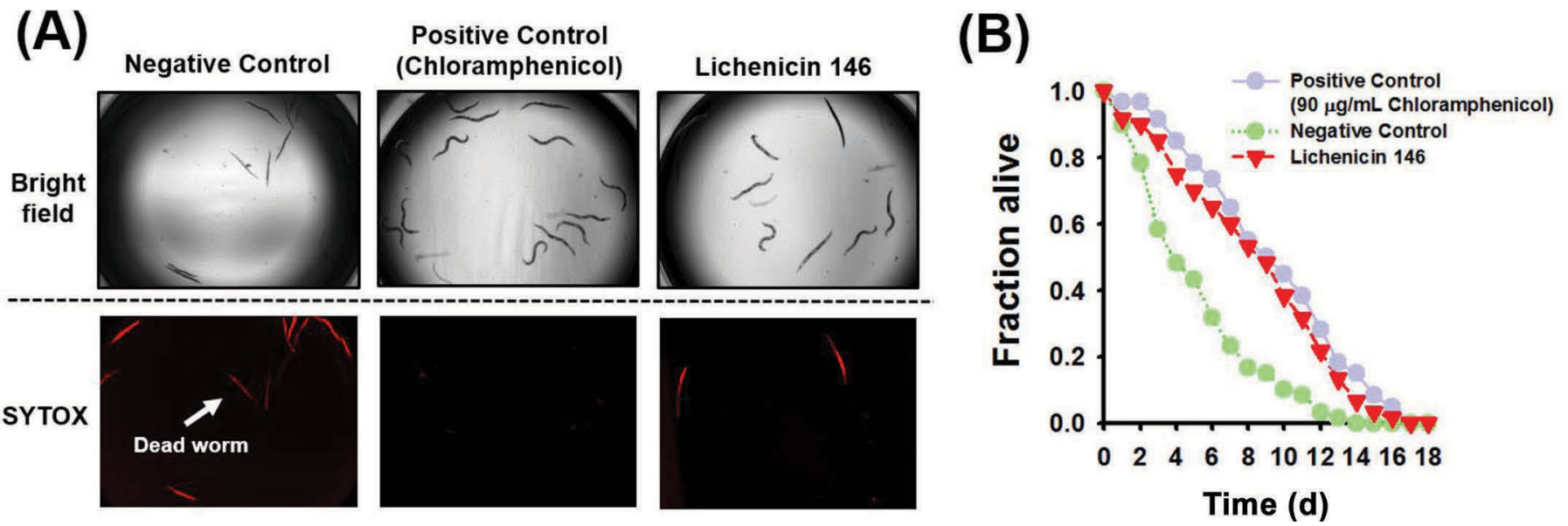

Figure 2. Caenorhabditis elegans-based in vivo platform for identifying bacteriocins produced by Bacillus licheniformis strain 146 (lichenicin 146) to combat mastitis-causing Staphylococcus aureus strain RF122. (A) Bright-field or SYTOX (Life Technologies, Carlsbad, CA) fluorescent images of $C$. elegans infected with Staph. aureus strain RF122 in the presence of lichenicin 146 for 3 d. In the bright-field images, live nematodes have a sinusoidal shape in the liquid infection assay, whereas dead nematodes appear as straight and rigid rods. Only dead worms were stained in the SYTOX-fluorescent images. (B) Lifespan of C. elegans infected with Staph. aureus strain RF122 in the presence of lichenicin 146 for 20 $\mathrm{d}$ using the manual killing method. Survival statistics: $P<0.0001$ for both chloramphenicol and lichenicin 146 compared with the negative control. As the negative and positive controls, we used medium alone and chloramphenicol at a concentration of $90 \mu \mathrm{g} / \mathrm{mL}$, respectively. Color version available online. 
(A)
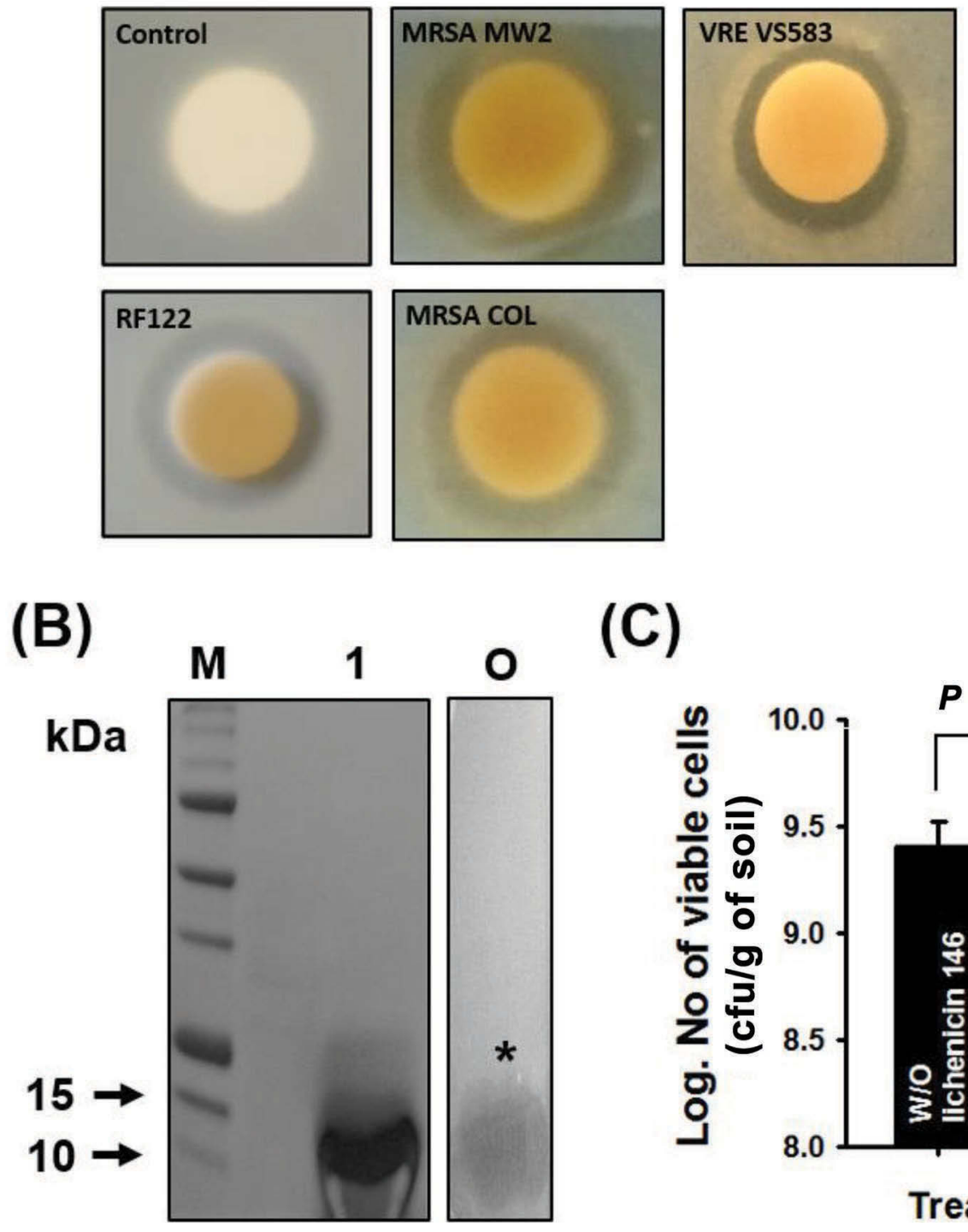

(C)

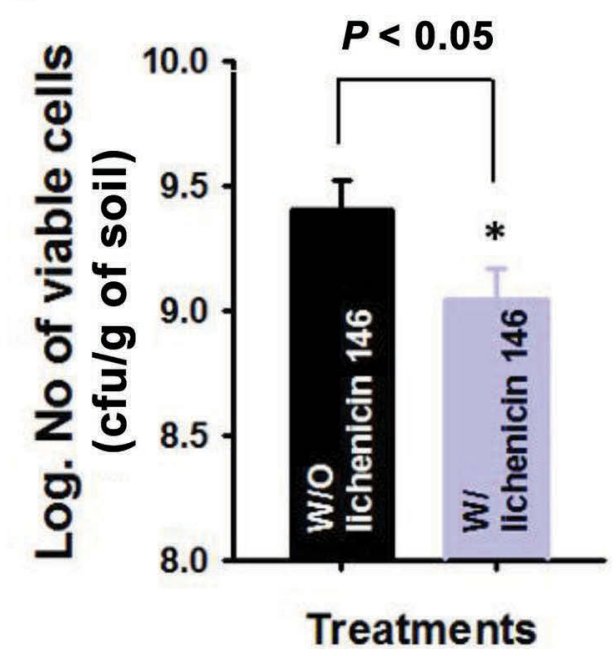

Figure 3. Detection of the antimicrobial activity of lichenicin 146 produced by Bacillus licheniformis strain 146. (A) Inhibitory activity of lichenicin 146 against mastitis-causing Staphylococcus aureus strain RF122 and antibiotic resistant pathogens including methicillin-resistant Staph. aureus (MRSA) strain MW2 and CLO, and vancomycin-resistant Enterococcus faecalis (VRE) strain VS583 according to the disk diffusion method. (B) Tricine-SDS-PAGE analysis of the lichenicin 146. Gel stained with Coomassie blue stain (M, Precision Plus Protein Dual Xtra Standards, Bio-Rad, Hercules, CA); lane 1, concentrated lichenicin 146 using cut-off membrane. In addition, the gel was overlaid with Staph. aureus strain RF122 cells in brain heart infusion soft agar and incubated overnight at $37^{\circ} \mathrm{C}$ (lane $\mathrm{O}$ ). Asterisk indicates the zone of inhibition with lichenicin 146 against Staph. aureus strain RF122. (C) The enumeration of total bacteria (including potential mastitis-causing pathogens) in dairy soil environment with or without lichenicin 146. Data are expressed as means \pm SD of 3 experiments. The asterisk indicates statistical significance determined using a Student's $t$-test $(P<0.05)$. Color version available online.

cins that could combat mastitis-causing Staph. aureus. The bacteriocin produced by B. licheniformis strain 146 is referred to as lichenicin 146 , and it was tested in further experiments.

To determine the characteristics of lichenicin 146, we performed SDS-PAGE and LC-MS/MS analyses. The
Tricine-SDS-PAGE results showed that lichenicin 146 had an estimated molecular mass of approximately 10 $\mathrm{kDa}$ and the active fraction possessed an antibacterial activity against Staph. aureus strain RF122 in a gel overlay assay (Figure 3B). To characterize lichenicin 146 more precisely, proteome analysis was conducted 
Table 1. Partial list of differentially expressed genes in mastitis-causing Staphylococcus aureus strain RF122 when treated with lichenicin 146 produced by Bacillus licheniformis strain 146 for $6 \mathrm{~h}$

\begin{tabular}{|c|c|c|}
\hline \multicolumn{3}{|l|}{ Transcription } \\
\hline SAB0133 & 220.5 & Transcriptional regulator \\
\hline$S A B 200 \% c$ & 8.0 & Predicted transcriptional regulator \\
\hline$S A B 0420 c$ & 6.9 & Transcriptional regulator \\
\hline$S A B 0063$ & 5.9 & Predicted transcriptional regulator \\
\hline SAB1521c & 13.9 & DNA repair protein \\
\hline \multicolumn{3}{|l|}{ Cell wall/membrane/envelope biogenesis } \\
\hline SAB0357 & 39.8 & Spore coat protein \\
\hline$S A B 1896 c$ & 38.1 & Spore coat protein \\
\hline$S A B 0993 c$ & 21.5 & Cell surface protein \\
\hline SAB0866 & 10.0 & Competence protein \\
\hline$S A B 0150$ & 6.2 & Membrane proteins related to metalloendopeptidase \\
\hline$S A B 1325 \mathrm{c}$ & -3.7 & Predicted membrane protein \\
\hline SAB0982 & -3.5 & Predicted membrane protein \\
\hline$S A B 1863 c$ & -3.5 & Predicted membrane protein \\
\hline$S A B 0290 c$ & -3.2 & Predicted membrane protein \\
\hline$S A B 1386 c$ & -3.1 & Predicted membrane protein \\
\hline SAB1044 & -3.4 & Protein required for the initiation of cell division \\
\hline \multicolumn{3}{|l|}{ Defense mechanisms } \\
\hline$S A B 1681 c$ & -15.0 & Lantibiotic modifying enzyme \\
\hline \multicolumn{3}{|l|}{ Function unknown } \\
\hline$S A B 2154 c$ & -3.3 & Uncharacterized conserved protein \\
\hline$S A B 1421 c$ & -2.7 & Uncharacterized conserved protein \\
\hline
\end{tabular}

with LC-MS/MS, which detected a protein with sequence coverage of $40 \%$ (the searched peptide number was 126 and the matched peptide number was 51). Using BLAST similarity search via the NCBI database, the protein sequence of lichenicin 146 was found to be highly homologous with a bacteriocin family protein (KJE33240.1). Bacillus spp., including Bacillus subtilis, Bacillus thuringiensis, Bacillus amyloliquefaciens, and B. licheniformis, produce low-molecular-weight bacteriocins (smaller than $10 \mathrm{kDa}$ ) that belong to the class II bacteriocin family (Barbosa et al., 2015). Thus, we propose that lichenicin 146 may also belong to the class II bacteriocin family due to its low molecular weight. Further research is needed to determine the specific anti-Staph. aureus feature of lichenicin 146 based on structural analysis coupled with crystallography.

Several reports indicated that nisin, as one of wellestablished bacteriocin, could be applied on the bovine mastitis (Malvisi et al., 2016), but they were critically limited, as nisin are only effective at low $\mathrm{pH}$. The results from bacterial-counting assay showed that total bacteria (including potential mastitis-causing pathogens) existed in dairy soil samples but was significantly reduced by the presence of lichenicin 146 (Figure 3C); hence, lichenicin 146 possesses antimicrobial activity on the neutral $\mathrm{pH}$ soil environment in dairy farms and influences the emergence of potential mastitis-causing pathogens. Importantly, recent studies showed that $B a$ cillus spp., including $B$. licheniformis, confer significant potential probiotic agents for feed additives (Sorokulova et al., 2008). Indeed, supplementation with Bacillus spp. may provide benefits for ruminal fermentation characteristics, milk production efficiency, and cow health (Luan et al., 2015). Also, B. licheniformis has several practical advantages on facile cultivation and low-cost to produce feed additives (Wang et al., 2016). Taken together, we proposed that $B$. licheniformis and lichenicin 146 is capable for applying on the dairy filed in safety respect as well as productive and economics.

In addition, RNA-Seq was performed to explore the gene regulation involved in the mode of action of lichenicin 146 against Staph. aureus strain RF122. Our transcriptome analysis showed that various genes were transcriptionally or post-transcriptionally regulated on treatment with lichenicin 146. In total, 23 genes were downregulated by more than 3 -fold, whereas 23 genes 
were upregulated (Table 1). In particular, the transcription levels of $S A B 0133, S A B 035 \%$, and $S A B 2383$, which encode transcription regulators, dramatically increased by 220.5-, 39.8-, and 4.8-fold, respectively. According to these results, specific transcriptional regulators are involved in bacterial physiology, including cell viability (Balleza et al., 2009). In addition, genes encoding cell surface or membrane proteins (SAB0993c, SAB0150, $S A B 0994 c$, and $S A B 2375 c$ ) were strongly upregulated. In general, class II bacteriocins primarily act by making the membranes of target cells permeable, probably via pore formation (Ennahar et al., 2000). Similar results were reported by Martínez et al. (2007), who found that several membrane protein-encoding genes were significantly upregulated after the treatment of target cells with a bacteriocin. Overall, our results suggest that lichenicin 146 strongly affects the physiology of the cell membrane as well as the network of transcriptional regulators in the cytoplasm of mastitis-causing Staph. aureus strain RF122.

In conclusion, we established a $C$. elegans-based screening platform to target mastitis-causing Staph. aureus as a direct in vivo tool for screening potential bacteriocins. Our in vivo platform is simple, rapid, cost-effective, and reliable, and we anticipate that it will facilitate the discovery of many more potential bacteriocin-producing bacteria to inhibit mastitis-causing pathogens, including antibiotic-resistant bacteria in the dairy field.

\section{ACKNOWLEDGMENTS}

This research was supported by the Cooperative Research Program for Agriculture Science \& Technology Development, Rural Development Administration, Republic of Korea (Project No. PJ01197801).

\section{REFERENCES}

Allison, J. R. 1985. Antibiotic residues in milk. Br. Vet. J. 141:9-16.

Balleza, E., L. N. López-Bojorquez, A. Martínez-Antonio, O. Resendis-Antonio, I. Lozada-Chávez, Y. I. Balderas-Martínez, S. Encarnación, and J. Collado-Vides. 2009. Regulation by transcription factors in bacteria: Beyond description. FEMS Microbiol. Rev. $33: 133-151$.

Barbosa, J., T. Caetano, and S. Mendo. 2015. Class I and class II lanthipeptides produced by Bacillus spp. J. Nat. Prod. 78:2850-2866.

Bouchard, D. S., L. Rault, N. Berkova, Y. Le Loir, and S. Even. 2013. Inhibition of Staphylococcus aureus invasion into bovine mammary epithelial cells by contact with live Lactobacillus casei. Appl. Environ. Microbiol. 79:877-885.

Dawkins, M. 2012. Animal Suffering: The Science of Animal Welfare. Springer Science \& Business Media, Berlin, Germany.

Ennahar, S., T. Sashihara, K. Sonomoto, and A. Ishizaki. 2000. Class IIa bacteriocins: Biosynthesis, structure and activity. FEMS Microbiol. Rev. 24:85-106.
Fitzgerald, J. R., S. R. Monday, T. J. Foster, G. A. Bohach, P. J. Hartigan, W. J. Meaney, and C. J. Smyth. 2001. Characterization of a putative pathogenicity island from bovine Staphylococcus aureus encoding multiple superantigens. J. Bacteriol. 183:63-70.

Haran, K. P., S. M. Godden, D. Boxrud, S. Jawahir, J. B. Bender, and S. Sreevatsan. 2012. Prevalence and characterization of Staphylococcus aureus, including methicillin-resistant Staphylococcus aureus, isolated from bulk tank milk from Minnesota dairy farms. J. Clin. Microbiol. 50:688-695.

Ikawaty, R., E. Brouwer, M. Jansen, E. Van Duijkeren, D. Mevius, J. Verhoef, and A. Fluit. 2009. Characterization of Dutch Staphylococcus aureus from bovine mastitis using a multiple locus variable number tandem repeat analysis. Vet. Microbiol. 136:277-284.

Irazoqui, J. E., E. R. Troemel, R. L. Feinbaum, L. G. Luhachack, B. O. Cezairliyan, and F. M. Ausubel. 2010. Distinct pathogenesis and host responses during infection of $C$. elegans by $P$. aeruginosa and S. aureus. PLoS Pathog. 6:e1000982.

Kim, Y., and E. Mylonakis. 2012. Caenorhabditis elegans immune conditioning with the probiotic bacterium Lactobacillus acidophilus strain NCFM enhances gram-positive immune responses. Infect. Immun. 80:2500-2508.

Klaenhammer, T. R. 1993. Genetics of bacteriocins produced by lactic acid bacteria. FEMS Microbiol. Rev. 12:39-85.

Lee, M. J., K. Na, S. K. Jeong, J. S. Lim, S. A. Kim, M. J. Lee, S. Y. Song, H. Kim, W. S. Hancock, and Y. K. Paik. 2014. Identification of human complement factor $\mathrm{B}$ as a novel biomarker candidate for pancreatic ductal adenocarcinoma. J. Proteome Res. 13:4878-4888.

Luan, S., M. Duersteler, E. A. Galbraith, and F. C. Cardoso. 2015. Effects of direct-fed Bacillus pumilus 8G-134 on feed intake, milk yield, milk composition, feed conversion, and health condition of pre- and postpartum Holstein cows. J. Dairy Sci. 98:6423-6432.

Malvisi, M., M. Stuknyte, G. Magro, G. Minozzi, A. Giardini, I. De Noni, and R. Piccinini. 2016. Antibacterial activity and immunomodulatory effects on a bovine mammary epithelial cell line exerted by nisin A-producing Lactococcus lactis strains. J. Dairy Sci. 99:2288-2296.

Martínez, B., A. L. Zomer, A. Rodríguez, J. Kok, and O. P. Kuipers. 2007. Cell envelope stress induced by the bacteriocin Lcn972 is sensed by the lactococcal two-component system CesSR. Mol. Microbiol. 64:473-486.

Miles, H., W. Lesser, and P. Sears. 1992. The economic implications of bioengineered mastitis control. J. Dairy Sci. 75:596-605.

Mortazavi, A., B. A. Williams, K. McCue, L. Schaeffer, and B. Wold. 2008. Mapping and quantifying mammalian transcriptomes by RNA-Seq. Nat. Methods 5:621-628.

Mungube, E. O., B.-A. Tenhagen, F. Regassa, M. Kyule, Y. Shiferaw, T. Kassa, and M. Baumann. 2005. Reduced milk production in udder quarters with subclinical mastitis and associated economic losses in crossbred dairy cows in Ethiopia. Trop. Anim. Health Prod. 37:503-512.

O'Shea, E. F., P. M. O'Connor, O. O'Sullivan, P. D. Cotter, R. P. Ross, and C. Hill. 2013. Bactofencin A, a new type of cationic bacteriocin with unusual immunity. MBio 4:e00498-13.

Park, M. R., E. S. Jeong, S. Oh, M. H. Song, J. K. Doo, Y. S. Jeong, Y. I. Moon, and Y. Kim. 2013. Rapid in vivo colonization screening of probiotic bacteria Isolated from human infants using Caenorhabditis elegans surrogate host. Korean J. Food Sci. Anim. Res. $33: 522-530$

Rajamuthiah, R., B. B. Fuchs, E. Jayamani, Y. Kim, J. Larkins-Ford, A. Conery, F. M. Ausubel, and E. Mylonakis. 2014. Whole animal automated platform for drug discovery against multi-drug resistant Staphylococcus aureus. PLoS ONE 9:e89189.

Riddle, D. L., T. Blumenthal, B. J. Meyer, and J. R. Priess. 1997. Transcription Factors and Transcriptional Regulation- $C$. elegans II. Cold Spring Harbor Laboratory Press, Cold Spring Harbor, NY.

Ruegg, P. L., and T. Tabone. 2000. The relationship between antibiotic residue violations and somatic cell counts in Wisconsin dairy herds. J. Dairy Sci. 83:2805-2809. 
Schägger, H., and G. Von Jagow. 1987. Tricine-sodium dodecyl sulfatepolyacrylamide gel electrophoresis for the separation of proteins in the range from 1 to $100 \mathrm{kDa}$. Anal. Biochem. 166:368-379.

Schukken, Y. H., J. Günther, J. Fitzpatrick, M. Fontaine, L. Goetze, O. Holst, J. Leigh, W. Petzl, H.-J. Schuberth, and A. Sipka. 2011. Host-response patterns of intramammary infections in dairy cows. Vet. Immunol. Immunopathol. 144:270-289.

Sears, P., J. Peele, M. Lassauzet, and P. Blackburn. 1995. Use of antimicrobial proteins in the treatment of bovine mastitis. Pages 17-18 in Proceedings of the 3rd International Mastitis Seminars. National Mastitis Reference Center, Kimron Veterinary Institute, Beit-Dagan, Israel.

Sorokulova, I. B., I. V. Pinchuk, M. Denayrolles, I. G. Osipova, J. M. Huang, S. M. Cutting, and M. C. Urdaci. 2008. The safety of two Bacillus probiotic strains for human use. Dig. Dis. Sci. 53:954-963.
Wang, Z., Z. He, K. A. Beauchemin, S. Tang, C. Zhou, X. Han, M. Wang, J. Kang, N. E. Odongo, and Z. Tan. 2016. Comparison of two live Bacillus species as feed additives for improving in vitro fermentation of cereal straws. Anim. Sci. J. 87:27-36.

Watts, J. L. 1988. Etiological agents of bovine mastitis. Vet. Microbiol. 16:41-66.

Yun, H. S., S. J. Son, S. N. Oh, J. N. Kim, H. S. Cho, S. W. Jo, and Y. H. Kim. 2014. Bacillus licheniformis isolated from Korean traditional food sources enhances the resistance of Caenorhabditis elegans to infection by Staphylococcus aureus. J. Microbiol. Biotechnol. 24:1105-1108. 